\title{
Modeling Develops to Estimate Leaf Area and Leaf Biomass of Lagerstroemia speciosa in West Vanugach Reserve Forest of Bangladesh
}

\author{
Niamjit Das \\ Department of Forestry and Environmental Science, Shahjalal University of Science and Technology, Sylhet-3114, Bangladesh \\ Correspondence should be addressed to Niamjit Das; niamjit.forestry@gmail.com
}

Received 25 February 2014; Accepted 17 March 2014; Published 17 April 2014

Academic Editors: J. Kaitera and G. Martinez Pastur

Copyright (C) 2014 Niamjit Das. This is an open access article distributed under the Creative Commons Attribution License, which permits unrestricted use, distribution, and reproduction in any medium, provided the original work is properly cited.

\begin{abstract}
Leaf area and leaf biomass have an important influence on the exchange of energy, light interception, carbon cycling, plant growth, and forest productivity. This study showed development and comparison of models for predicting leaf area and leaf biomass of Lagerstroemia speciosa on the basis of diameter at breast height and tree height as predictors. Data on tree parameters were collected randomly from 312 healthy, well-formed tree species that were considered specifically for full tree crowns. Twenty-four different forms of linear and power models were compared in this study to select the best model. Two models $\left(\mathrm{M}_{10}\right.$ and $\left.\mathrm{M}_{22}\right)$ for the estimation of leaf area and leaf biomass were selected based on $R^{2}$, adjusted $R^{2}$, root mean squared error, corrected akaike information criterion, Bayesian information criterion and Furnival's index, and the three assumptions of linear regression. The models were validated with a test data set having the same range of $\mathrm{DBH}$ and tree height of the sampled data set on the basis of linear regression Morisita's similarity index. So, the robustness of the models suggests their further application for leaf area and biomass estimation of $L$. speciosa in West Vanugach reserve forest of Bangladesh.
\end{abstract}

\section{Introduction}

Leaf area $\left(A_{1}\right)$ and leaf biomass $\left(B_{1}\right)$ estimation are significant basics of studying gas-exchange processes and modeling ecosystems. It is key traits in ecophysiological studies that determine assessing photosynthetic efficiency, evapotranspiration, atmospheric deposition, biogenic volatile organic emissions, light interception, and other ecosystem processes. Leaf area is valuable for the evaluation and understanding of individual tree growth models [1], biogeochemical models [2], and gap models [3]. It is defined as the one-sided projected surface area which is an important consequence for the interception of radiant energy, the absorption of carbon dioxide, and the circulation of water between the foliage and the atmosphere [4]. Leaf biomass constitutes one of the most important pools of essential nutrients, which is vital for forest nutrient cycling [5], including carbon cycling in a forest ecosystem. Leaf biomass estimates were considerably improved when additional biometric information relating to crown structure was added, whereas canopy $B_{1}$ is the product of leaf dry matter content and leaf area index [6]. Interspecific variation in $A_{1}$ and $B_{1}$ has been connected with climatic variation, geology, altitude, or latitude, where heat stress, cold stress, drought stress, and high-radiation stress all tend to select relatively small leaves. Within climatic zones, leaf-size variation can also be linked to allometric factors (plant size, twig size, anatomy, and architecture) and ecological strategy [7].

Measurement of the destructive (direct) method of $A_{1}$ and $B_{1}$ is very time consuming, labour intensive, and ecounfriendly and depends on very small samples. But, nondestructive (indirect) methods were found user friendly and less expensive and can give accurate $A_{1}$ and $B_{1}$ estimates $[8,9]$. To quantify the $A_{1}$ and $B_{1}$ of individual trees, the relationship between $A_{1}$ and $B_{1}$ with $\mathrm{DBH}$ (diameter at breast height) and height are widely used [10]. This relationship differs between tree species and to some degree also within a tree species [11, 12 ] and needs to be established for each species in question. For the development of models, the power function $(y=$ $\left.a x^{b}\right)$ form is widely used in biological sciences particularly 


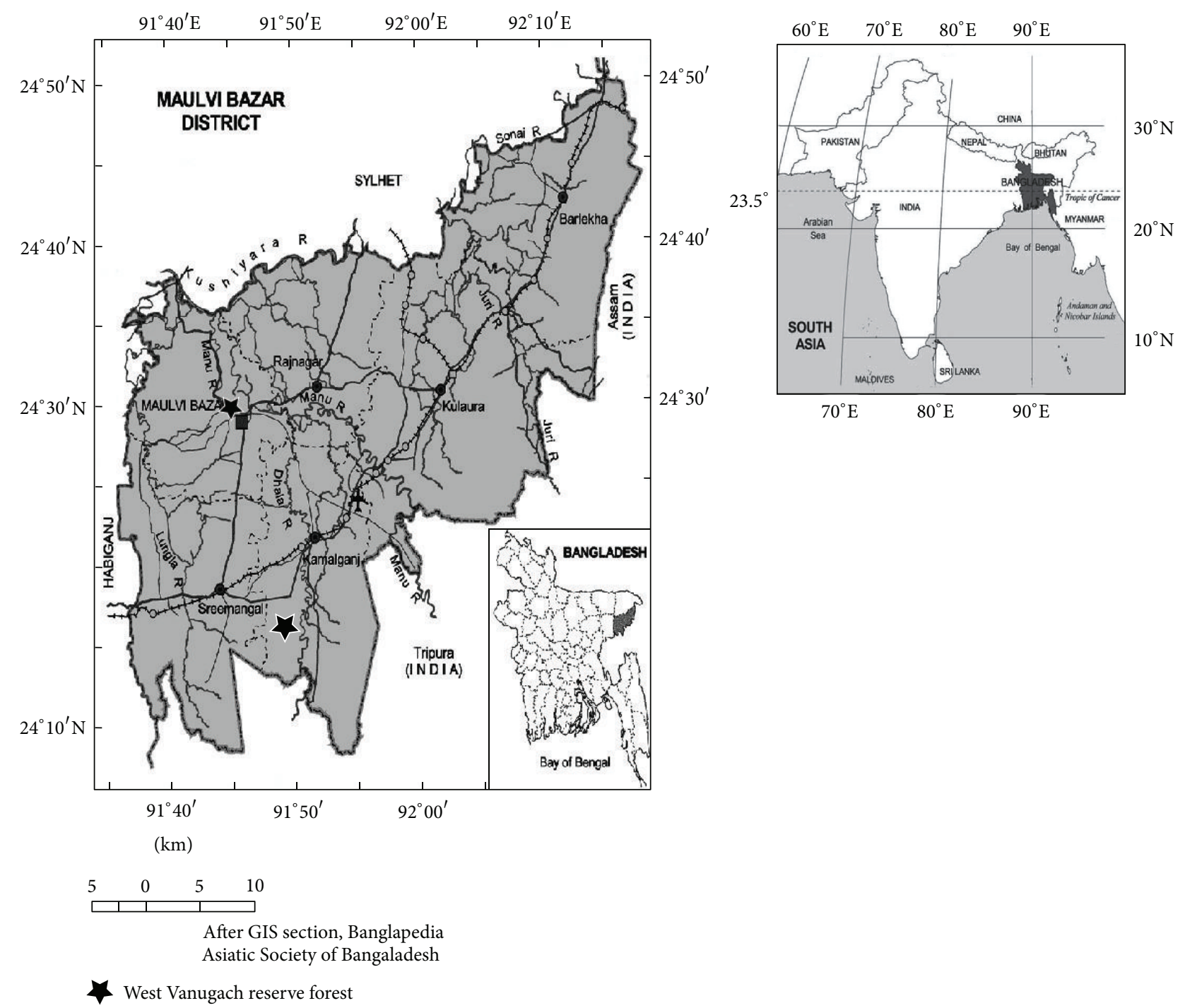

FIGURE 1: Study site in West Vanugach reserve forest of Bangladesh.

for these relationships [13]. But, in practice, the default nonlinear technique assumes homogeneity of errors that cannot be safely assumed with most model data. At present, models are developed by fitting a linear relationship between log-transformed diameter and leaf data. Although the logtransformed linear equation is mathematically equivalent to the power equation, they are not identical in the statistical sense [14]. However, many model characteristics of organisms are multiplicative by nature and thus fitting models to logtransformed data is perfectly acceptable because accounting for proportional rather than absolute variation is most important [15].

Lagerstroemia speciosa (L.) is the dominant tree both spatially and vertically in the forests of Bangladesh. It is well distributed in natural forests as well as in plantation forests [16]. It is also found at low to medium altitudes in comparatively open habitats, in disturbed or secondary forest and grassland. The habitat may vary from well drained to occasionally flooded but not peat soil and it is resistant to fire. L. speciosa is the most important wood species in parts of South and Southeast Asia [16], but to estimate $A_{1}$ and $B_{1}$ relationships of this species is not available. So, the main goal of my study was to develop and compare models of L. speciosa that will help to estimate $A_{1}$ and $B_{1}$ of the species in reserve forest of Bangladesh.

\section{Materials and Methods}

2.1. Site Description. The field work was conducted at the West Bhanugach Reserved Forest (2,740 ha) on the Moulvibazar Forest Range $\left(24^{\circ} 19^{\prime} 11^{\prime \prime} \mathrm{N}, 91^{\circ} 47^{\prime} 1^{\prime \prime} \mathrm{E}\right.$, altitude of $45 \mathrm{~m}$ ) in tropical semievergreen forest, Bangladesh (Figure 1). The soil of this forest is alluvial brown sandy clay loam to clay loam. Average annual rainfall is $4,332 \mathrm{~mm}$ and January is the coldest month (minimum temperature around $11^{\circ} \mathrm{C}$ ), while May and October are the hottest months (average maximum temperature around $33^{\circ} \mathrm{C}$ ). The relative humidity is about 75\% during December and over 92\% during July-August [17]. 
This forest stand is a mixed forest stand and its vegetation is recognized as old growth plantation forest. It includes 78 species of trees, 14 species of shrubs, 42 species of herbs, and 25 species of climbers [18].

2.2. Species Description. Lagerstroemia speciosa (L.) is a medium-sized tree growing to 20 meters tall, much branched deciduous tree, with smooth and flaky bark [16]. Its leaves are opposite, elliptic, or oblong-lanceolate, $8.5-20.0 \mathrm{~cm}$ long and $3.0-7.5 \mathrm{~cm}$ broad, acuminate at the apex, acute to rounded at the base, and glabrous and finely reticulate on both surfaces, have lateral nerves $8-12$ on either half, prominent beneath, and petioles $5-9 \mathrm{~mm}$ long, and are stout. Its wood is strong and fairly durable and is used for carts, furniture, and house posts. The root is considered as an astringent, stimulant, and febrifuge and due to the tree's dense and wide spreading root system, it is used in erosion control. Its extracts have been used as traditional medicines and are effective in controlling diabetes and obesity. A leaf poultice is used to relief malarial fever and is applied on cracked feet. It is planted in forests, edges of forest streams, swamps, ditches, and river banks. It is growing in South East Asia, Bangladesh, India, and Philippines and it is also widely cultivated as an ornamental plant in tropical and subtropical areas [19].

2.3. Field Measurements. Leaf, DBH, and tree height data were collected for three hundred twelve sampled healthy wellformed $L$. speciosa tree species with full crown by maintaining the protocols for standardized and easy measurement of plant functional traits worldwide developed by Cornelissen et al. 2003. Field sampling occurred in the rainy season during which $A_{1}$ and $B_{1}$ were maximum. Diameter at breast height (DBH; at $1.3 \mathrm{~m}$ height from ground level) and tree height $(H)$ was measured with Suunto clinometers (Suunto PM5360, Vantaa, Finland) and tree calipers (Haglöf Graduated Aluminum Tree Caliper, Ben Meadows, Janesville, Wisconsin, USA). Data on tree parameters are usually measured and collected after harvesting for improving data accuracy $[6,20]$. Though using nondestructive methods is a highly reliable option [21] where whole tree removal is not possible, as is the case in Bangladeshi reserve forests [22], leaf data were collected manually (by climbing the tree). To retain high data accuracy, stratified random sampling was used for calculation of the leaf number per individual tree. Thereafter, the following steps were performed to count the leaves of each sampled tree: (I) the diameter of all of the main branches was measured; (II) the diameter of the main branch closest to the mean diameter was selected as the model main branch (MMB); (III) subbranches of all main branches were counted; (IV) three subbranches were selected randomly from the MMB; (V) twigs of each subbranch were counted and the mean twig number per subbranch was calculated; (VI) three twigs were selected randomly from each selected subbranch; (VII) the average number of leaves per twig was calculated; (VIII) the leaf number per subbranch was calculated by multiplying the mean twig number per subbranch and mean leaf number per twig; and (IX) the total leaf number per tree was calculated by multiplying the total number of subbranches and estimated leaf number per subbranch [9]. The leaves were categorized into small, medium, and large size and fifteen leaves of each category were collected according to different directions and heights of a tree. A total of fortyfive samples of leaves were taken from each sampled tree and packed in a plastic bag. The leaf area of each leaf sample was measured with a leaf area meter (CI-202, CID, Inc., Vancouver, Washington, USA) for small and medium leaves and Adobe Photoshop CS5 software for large leaves. Data of $\mathrm{DBH}$, height, leaf samples, and total leaf number per tree from additional 40 trees were collected and used as a test data set for validating the models. The projected leaf area for each sample tree $\left(A_{1}, \mathrm{~m}^{2}\right)$ was calculated by multiplying the average leaf area and total leaf number. Thickness of each sample leaf was estimated with digital caliper (Absolute Digimatic CD-6" CS, Mitutoyo Corporation, Kanagawa, Japan) and the fresh mass of each leaf was measured with a balance meter. Measured leaves were oven-dried at $65^{\circ} \mathrm{C}$ for $72 \mathrm{~h}$ and weighed to determine fresh mass: dry mass ratios. Total leaf volume per tree was estimated by multiplying total leaf area and leaf thickness. Leaf density was calculated by dividing by the average leaf fresh mass and the leaf volume of forty-five sample leaf in a tree. Total leaf biomass $\left(B_{1}, \mathrm{~kg}\right)$ per tree was estimated by multiplying the total leaf volume and leaf density.

2.4. Statistical Analysis. Regression analysis was used to evaluate the appropriateness of each of the two independent variables $(x)$ : height $(\mathrm{m})$ and $\mathrm{DBH}(\mathrm{cm})$, as estimators of total $A_{1}$ and $B_{1}$ (dependent variables $=y$ ) for $L$. speciosa by using $R$ statistical software version 2.15 .2 and SPSS 17 software (SPSS, ver. 17, Chicago, IL, USA). The data with two regression models (linear and power) was analyzed. At first, scatter plots were used to see whether the relationship between independent and dependent variables was linear. Secondly, given the presence of heteroscedasticity, power models transformed the data for linear regression using natural logarithmic. A total of twenty-four models were developed using DBH and height for the best model selection (Table 2). The performance of the developed models was evaluated by examining the goodness of fit $\left(R^{2}\right.$ and adjusted $R^{2}$ ), root mean squared error (RMSE), corrected akaike information criterion (AICc), Bayesian information criterion (BIC), and Furnival's index (FI). Thus, to select between models, the corrected akaike information criterion (AICc) for each model was then computed as

$$
\mathrm{AICc}=2 k-2 \ln (L)+\frac{2 k(k+1)}{n-k-1}
$$

where $n$ is the sample size, $k$ is the number of parameters in the statistical model, and $L$ is the corresponding likelihood [23]. The formula for the BIC (Bayesian information criterion) is

$$
\mathrm{BIC}=n \cdot \ln \left(\widehat{\sigma_{e}^{2}}\right)+k \cdot \ln (n),
$$

where $\widehat{\sigma_{e}^{2}}$ is the error variance [23]. For models with different dependent variables using $R^{2}$ to compare them could sometimes produce false results [24]. So, Furnival's index 
[25] which is able to compare models of different dependent variables or weights was used to compare the logarithmic and nonlogarithmic models. The index is calculated as follows:

$$
\mathrm{FI}=\frac{1}{\left[f^{\prime}(Y)\right]} \sqrt{\mathrm{MSE}}
$$

where $f^{\prime}(Y)$ is the derivative of the dependent variable with respect to $A_{1}$ and $B_{1}$, MSE is the mean square error of the fitted model, and the square bracket ([]) is the geometric mean. After that, the three regression assumptions were used to judge the consistency of the models for the residues: (I) no outlier, (II) the distribution of these residuals should be normal with mean $=0$ and a constant variance and (III) the data points must be independent [26]. The Durbin-Watson test was used to check for autocorrelation. Though logarithmic transformation is reported to increase the statistical validity of regression analysis by homogenising variance, it introduces a slight downward bias when data are back-transformed to arithmetic units [27]. To account for the bias, the back-transformed results from logarithmic unit are usually multiplied by a correction factor. Consequently, a correction factor (CF) was calculated for all logarithmic models. The CF is given by the following [28]:

$$
\mathrm{CF}=\exp ^{\left((\mathrm{SEE} * 2.303)^{2} / 2\right)},
$$

where SEE is the standard error of the estimate.

For validation of the models, the observed $A_{1}$ and $B_{1}$ data regressed from a test data set $(n=40)$ against the predicted $A_{1}$ and $B_{1}$ using linear regression. As a measure of distance between observed and predicted values, Morisita's [29] dissimilarity index $\left(D_{M}\right)$ was calculated as follows:

$$
D_{M}=\frac{(1 / n) \sum_{i=1}^{n}\left(y_{i}-y_{i}^{p}\right)^{2}}{(1 / n)\left(\sum_{i=1}^{n} y_{1}^{2}+\left(\sum_{i=1}^{n} y_{i}^{p}\right)^{2}\right)},
$$

where $y_{i}=$ observed $A_{1}$ and $B_{1}$ of the sampled data and $y_{i}^{p}=$ predicted $A_{1}$ and $B_{1}$. Note that $1-D_{M}$ is essentially Morisita's measure of niche overlap or similarity [30].

\section{Results}

3.1. Model Development. DBH and tree height of sampled individuals of $L$. speciosa ranged from 7.52 to $65.16 \mathrm{~cm}$ and 3.27 to $19.01 \mathrm{~m}$, respectively, and the $A_{1}$ and $B_{1}$ of sampled trees ranged from 36.20 to $141.31 \mathrm{~cm}^{2}$ and 0.35 to $1.26 \mathrm{~g}$, respectively. In addition, the range of $\mathrm{DBH}$ and $H$ data in the model test data set fell within the boundary of the sampled data set (Table 1). Table 3 summarizes the different models derived to predict $A_{1}$ and $B_{1}$ with $\mathrm{DBH}$ and $H$ as the independent variable. For the development of the best model, 24 different model forms were determined (Table 2). Model $\mathrm{M}_{10}$ and $\mathrm{M}_{22}$ were found to be the best predictor for $A_{1}$ and $B_{1}$ estimation, respectively. Whereas the RMSE value was the lowest and the goodness of fit $\left(R^{2}\right.$ and adjusted $\left.R^{2}\right)$ was highly significant and explained more than $96 \%$ variation for the selected models $\left(\mathrm{M}_{10}\right.$ and $\left.\mathrm{M}_{22}\right)$. To compare the models,
TABLE 1: General characteristics of L. speciosa species.

\begin{tabular}{lccc}
\hline Variables & Mean & SD & Range \\
\hline DBH $(\mathrm{cm})$ & 27.6069 & 14.4302 & $7.52-65.16$ \\
Height $(\mathrm{m})$ & 12.4225 & 2.8879 & $3.27-19.01$ \\
Validation DBH $(\mathrm{cm})$ & 27.0027 & 12.9432 & $7.65-64.85$ \\
Validation height $(\mathrm{m})$ & 11.9863 & 2.6372 & $3.24-18.79$ \\
Individual leaf area $\left(\mathrm{cm}^{2}\right)$ & 88.6291 & 9.3614 & $36.20-141.31$ \\
Individual dry leaf biomass $(\mathrm{g})$ & 0.8534 & 0.0526 & $0.35-1.26$ \\
\hline
\end{tabular}

TABLE 2: Twenty-four models used in this study.

\begin{tabular}{ll}
\hline Model number & Models \\
\hline $\mathrm{M}_{1}$ & $A_{1}=x_{o}+x_{1} \mathrm{DBH}$ \\
$\mathrm{M}_{2}$ & $A_{1}=x_{o}+x_{1} H$ \\
$\mathrm{M}_{3}$ & $A_{1}=x_{o}+x_{1}(\mathrm{DBH} \times H)$ \\
$\mathrm{M}_{4}$ & $A_{1}=x_{o}+x_{1} \mathrm{DBH}+x_{2} H$ \\
$\mathrm{M}_{5}$ & $A_{1}=x_{o}+x_{1} \mathrm{DBH}+x_{2} \mathrm{DBH}^{2}$ \\
$\mathrm{M}_{6}$ & $A_{1}=x_{o}+x_{1} H+x_{2} H^{2}$ \\
$\mathrm{M}_{7}$ & $\ln \left(A_{1}\right)=x_{o}+x_{1} \ln (\mathrm{DBH})$ \\
$\mathrm{M}_{8}$ & $\ln \left(A_{1}\right)=x_{o}+x_{1} \ln (H)$ \\
$\mathrm{M}_{9}$ & $\ln \left(A_{1}\right)=x_{o}+x_{1} \ln (\mathrm{DBH} \times H)$ \\
$\mathrm{M}_{10}$ & $\ln \left(A_{1}\right)=x_{o}+x_{1} \ln (\mathrm{DBH})+x_{2} \ln (H)$ \\
$\mathrm{M}_{11}$ & $\ln \left(A_{1}\right)=x_{o}+x_{1} \ln (\mathrm{DBH})+x_{2} \ln \left(\mathrm{DBH}^{2}\right)$ \\
$\mathrm{M}_{12}$ & $\ln \left(A_{1}\right)=x_{o}+x_{1} \ln (H)+x_{2} \ln \left(H^{2}\right)$ \\
$\mathrm{M}_{13}$ & $B_{1}=x_{o}+x_{1} \mathrm{DBH}$ \\
$\mathrm{M}_{14}$ & $B_{1}=x_{o}+x_{1} H$ \\
$\mathrm{M}_{15}$ & $B_{1}=x_{o}+x_{1}(\mathrm{DBH} \times H)$ \\
$\mathrm{M}_{16}$ & $B_{1}=x_{o}+x_{1} \mathrm{DBH}+x_{2} H$ \\
$\mathrm{M}_{17}$ & $B_{1}=x_{o}+x_{1} \mathrm{DBH}+x_{2} \mathrm{DBH}$ \\
$\mathrm{M}_{18}$ & $B_{1}=x_{o}+x_{1} H+x_{2} H^{2}$ \\
$\mathrm{M}_{19}$ & $\ln \left(B_{1}\right)=x_{o}+x_{1} \ln (\mathrm{DBH})$ \\
$\mathrm{M}_{20}$ & $\ln \left(B_{1}\right)=x_{o}+x_{1} \ln (H)$ \\
$\mathrm{M}_{21}$ & $\ln \left(B_{1}\right)=x_{o}+x_{1} \ln (\mathrm{DBH} \times H)$ \\
$\mathrm{M}_{22}$ & $\ln \left(B_{1}\right)=x_{o}+x_{1} \ln (\mathrm{DBH})+x_{2} \ln (H)$ \\
$\mathrm{M}_{23}$ & $\ln \left(B_{1}\right)=x_{o}+x_{1} \ln (\mathrm{DBH})+x_{2} \ln \left(\mathrm{DBH}^{2}\right)$ \\
$\mathrm{M}_{24}$ & $\ln \left(B_{1}\right)=x_{o}+x_{1} \ln (H)+x_{2} \ln \left(H^{2}\right)$ \\
\hline &
\end{tabular}

the AICc and BIC values were calculated and the results are presented in Table 3. The AICc and BIC values for models $M_{10}$ and $M_{22}$ were lower than that of other tested models indicating statistical robustness of the selected models. Based on Furnival's index (FI) of fit, models $\mathrm{M}_{10}$ and $\mathrm{M}_{22}$ performed better in both $A_{1}$ and $B_{1}$ estimation, whereas the FI values for both models were lower ( 0.36 and 0.47 , respectively) than that of other tested models.

To avoid any confusion, the three regression assumptions were checked to select the best model. A good model should conform to all valid statistical assumptions [26]. First assumption, residual analysis of models $\mathrm{M}_{10}$ and $\mathrm{M}_{2}$, showed that the values of standard residual were 2.93 and 2.48, respectively. A model to be outlier free requires that the value of standard residual must be below 3 [26]. In both models this requirement was fulfilled. The normality of residuals was measured for selected models by histogram and normal 


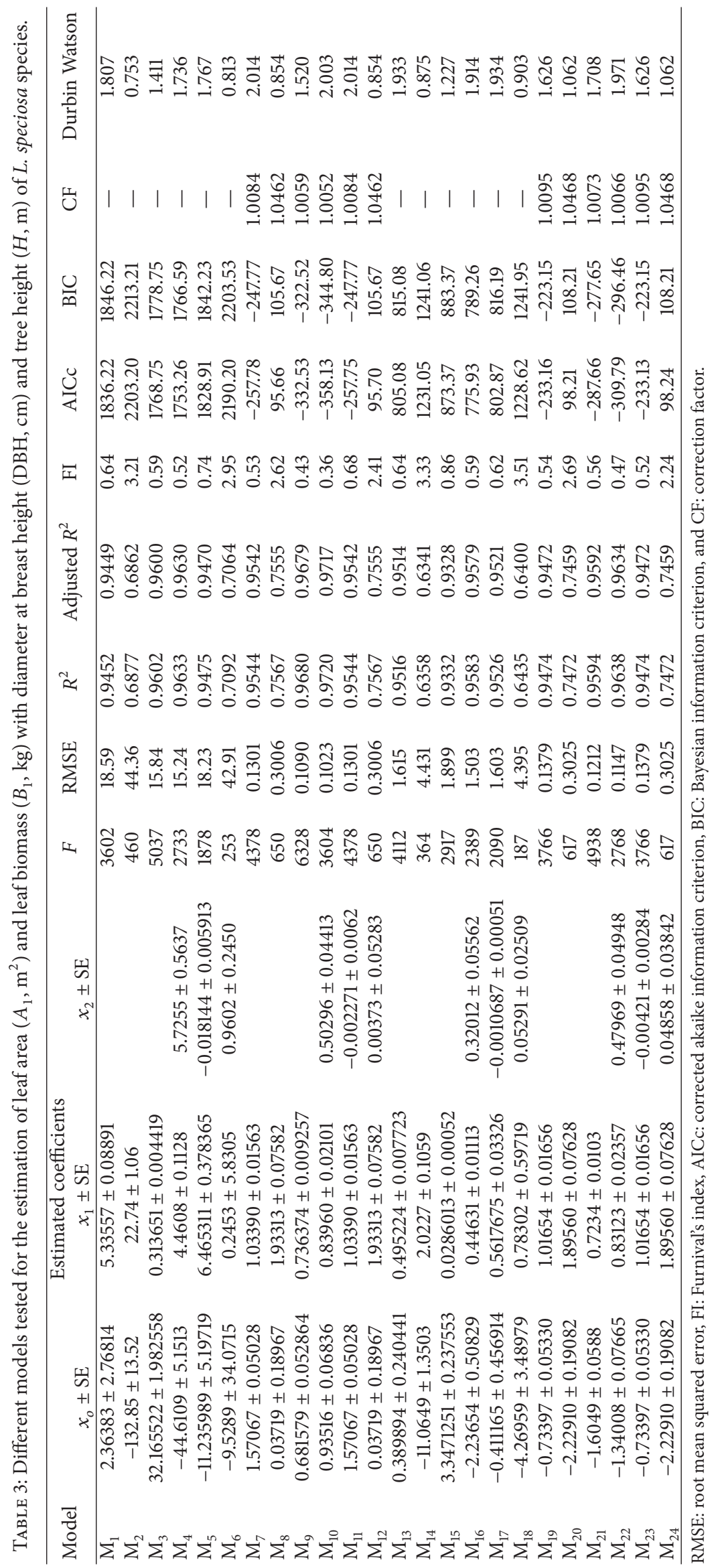




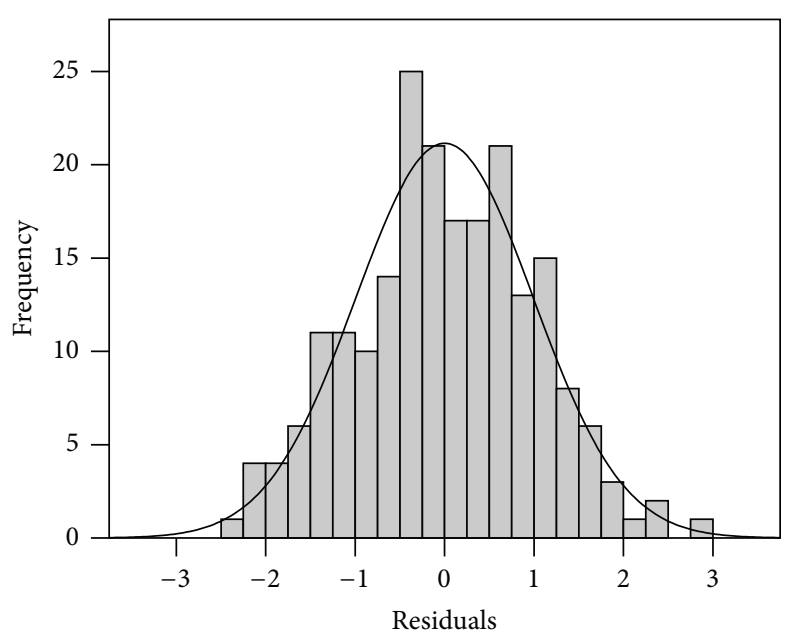

(a)

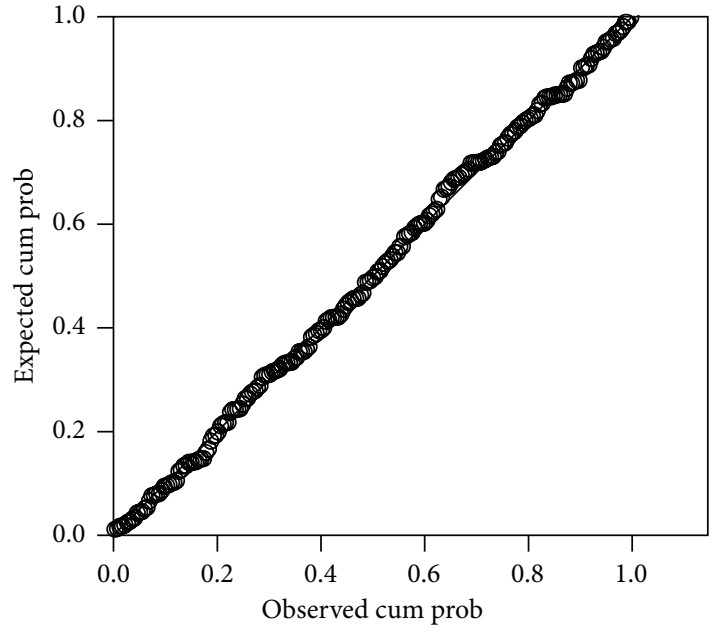

(b)

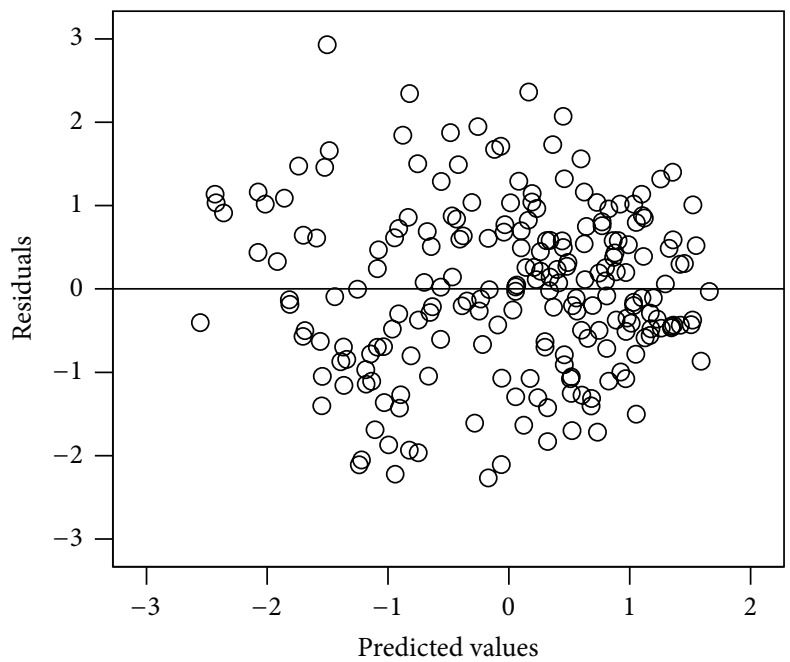

(c)

Figure 2: Residual distribution (a), normal P-P plot of regression standardized residuals (b), and scatter plot of residuals (c) for model $\mathrm{M}_{10}$.

probability plot. The distribution of the residual satisfies the normality assumptions for both models $\mathrm{M}_{10}$ (Figures 2(a) and 2(b)) and $\mathrm{M}_{22}$ (Figures 3(a) and 3(b)). Second assumption, diagnosis for constant variance, was done by plotting the regression standardized residuals and predicted values in a scatter plot. It was shown that the scatter of the residual points was randomly distributed (Figures 2(c) and 3(c)). Thus it can be concluded that the variance was constant for both models. Third assumption, the Durbin-Watson statistic, lies in the range $0.0-4.0$. A value of 2 or nearly 2 indicates that there is independence of the data points [31]. This range of the selected models was 2.003 for $A_{1}$ and 1.971 for $B_{1}$. Thus, the independence assumption was satisfied for both models. However, due to the systematic bias introduced by logarithmic transformation of data, correction factor is normally calculated for logarithmic transformed models so as to account for the bias. Correction factors showed a rather narrow variation for $A_{1}$ and $B_{1}$ (Table 3 ).
As a result, the final model of $A_{1}$ is

$$
\begin{aligned}
A_{1}=\exp ( & 0.93516+0.83960 \times \ln (\mathrm{DBH}) \\
& +0.50296 \times \ln (H)), \\
\text { or } A_{1}= & 2.547621 \times(\mathrm{DBH})^{0.83960} \times(H)^{0.50296} .
\end{aligned}
$$

The bias corrected model is $A_{1}=2.547621 \times(\mathrm{DBH})^{0.83960} \times$ $(H)^{0.50296} \times 1.005246=2.560986 \times(\mathrm{DBH})^{0.83960} \times(H)^{0.50296}$.

The final model of $B_{1}$ is

$$
\begin{aligned}
B_{1}=\exp ( & -1.34008+0.83123 \times \ln (\mathrm{DBH}) \\
& +0.47969 \times \ln (\mathrm{H})), \\
\text { or } B_{1}= & 0.261825 \times(\mathrm{DBH})^{0.83123} \times(\mathrm{H})^{0.47969} .
\end{aligned}
$$

The bias corrected model is $B_{1}=0.261825 \times(\mathrm{DBH})^{0.83123} \times$ $(H)^{0.47969} \times 1.0066=0.263553 \times(\mathrm{DBH})^{0.83123} \times(H)^{0.47969}$. 


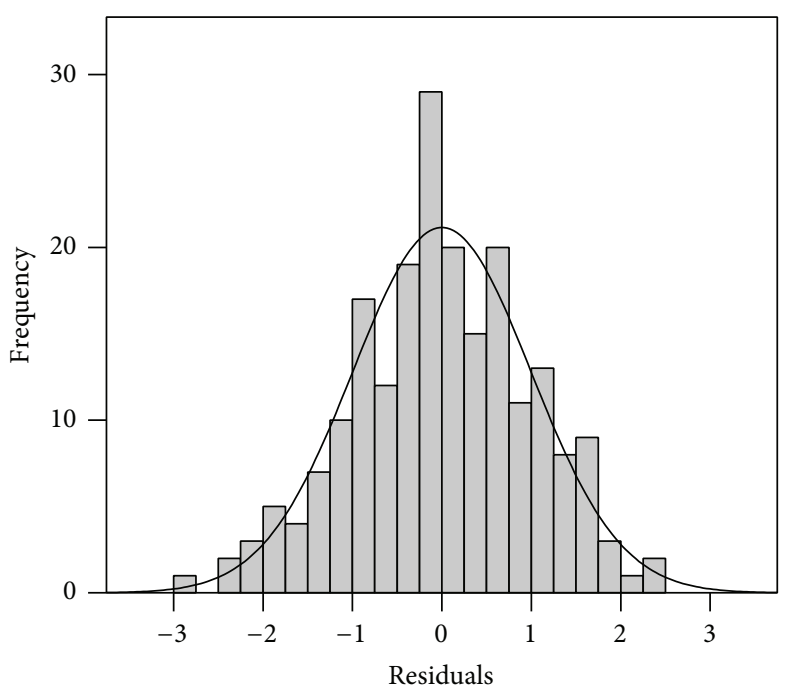

(a)

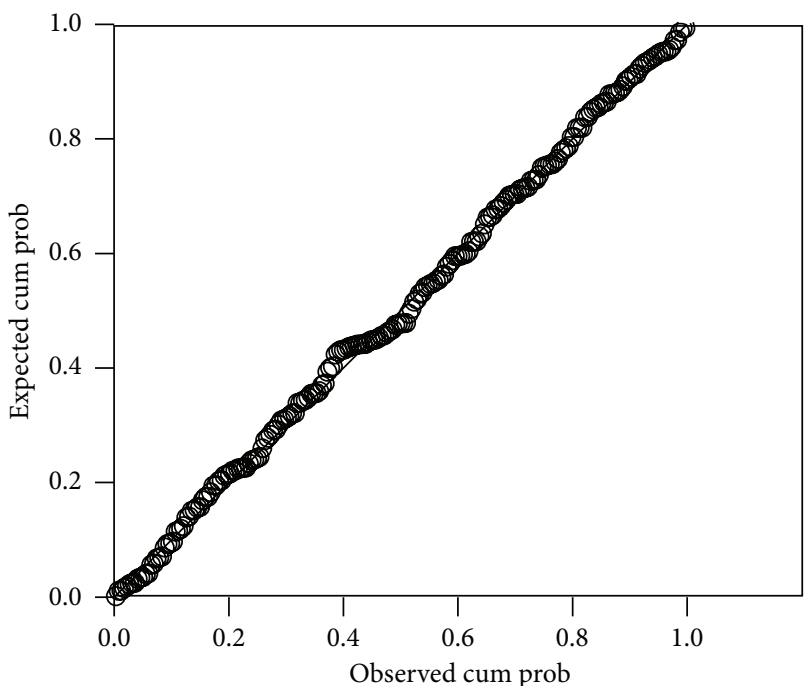

(b)

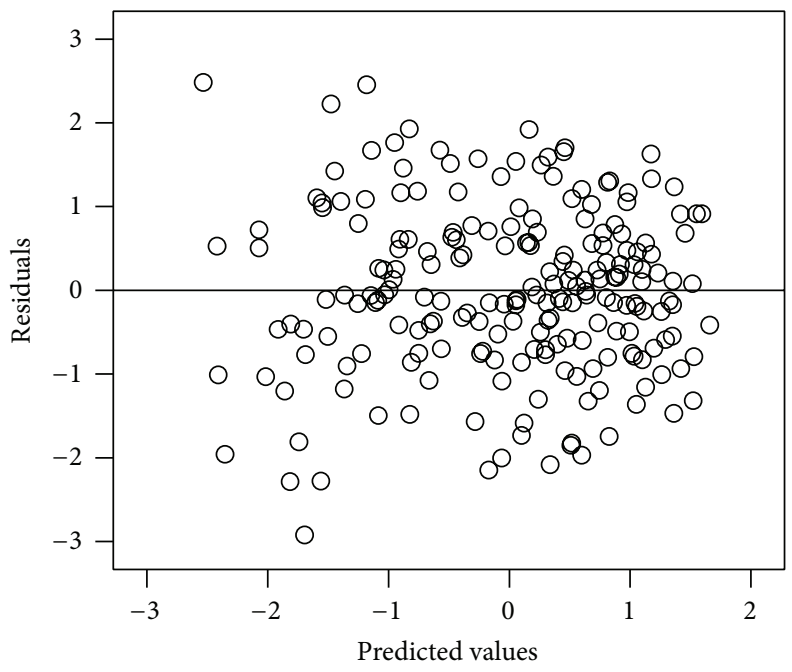

(c)

FiguRE 3: Residual distribution (a), normal P-P plot of regression standardized residuals (b), and scatter plot of residuals (c) for model $\mathrm{M}_{22}$.

3.2. Model Validation. In the model validation, the goodness of fit $\left(R^{2}\right)$ showed that there was a highly reliable relationship between predicted and observed data for $A_{1}$ and $B_{1}$. The $R^{2}$ values between them for models using $A_{1}$ or $B_{1}$ were 0.9716 and 0.9736, respectively (Figure 4). Morisita's [29] index of similarity $\left(1-D_{M}\right)$ was 0.994836 for $A_{1}$ and 0.993567 for $B_{1}$ (almost 1), which indicated that the models can predict $A_{1}$ and $B_{1}$, outside the sampled data set, effectively.

\section{Discussion}

Different combinations and forms of model of diameter and tree height were used to select the best models $\left(\mathrm{M}_{10}\right.$ and $\left.\mathrm{M}_{22}\right)$ that are more than $96 \%$ variation and lower RMSE, AICc, BIC, FI value in measuring $A_{1}$ and $B_{1}$ of L. speciosa. After that, logarithmic transformation induces a systematic bias in the estimation, which was corrected using a CF in the final model [27]. Given the paucity of models for this forest, I expect these models to prove valuable in future research that requires estimates of $A_{1}$ and $B_{1}$ of this species. Burton et al. [32] found that $\mathrm{DBH}$ is the best predictor for estimating $A_{1}$ and $B_{1}\left(R^{2}>0.90\right)$. Using a nondestructive sampling technique for $A_{1}$ estimation, Grace [33] found that $\mathrm{DBH}$ could explain $91 \%$ variation in $A_{1}$ of Acacia Koa. Although sapwood area (AS) or sapwood volume has proved a good predictor of tree canopy properties in different temperate in the past $[34,35]$, it has not been measured in this study or any national forest inventories in Bangladesh. However, Turner et al. [36] found that, in Pseudotsuga menziesii, the $A_{1}$ estimates based on $\mathrm{DBH}$ were more accurate than those on AS. So, I excluded AS from this study. Other studies found higher [37-41] correlations with DBH. Then it provides support for estimation of $A_{1}$ and $B_{1}$ which are positively correlated to $\mathrm{DBH}$ and $H$ [20]. Sarker et al. [9] 


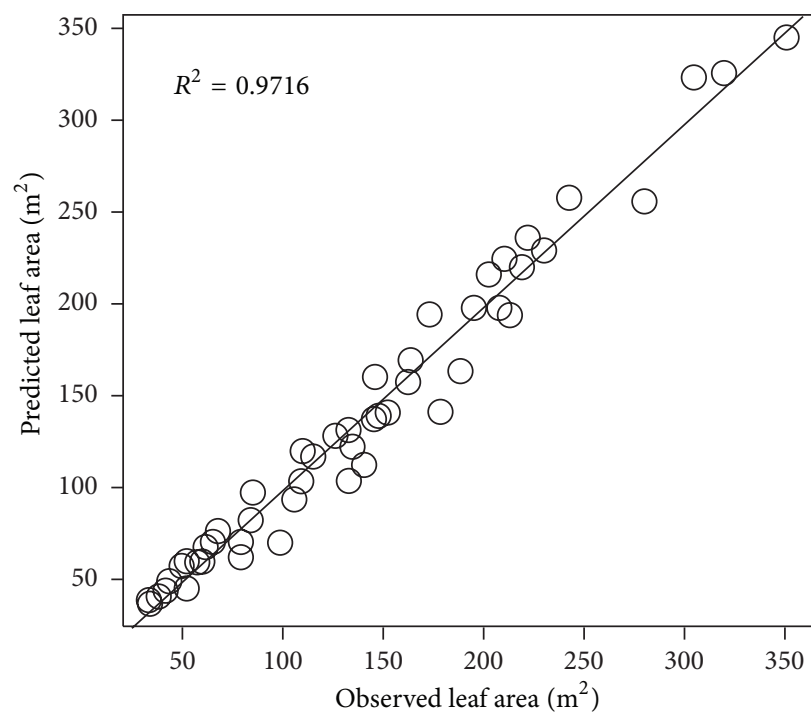

(a)

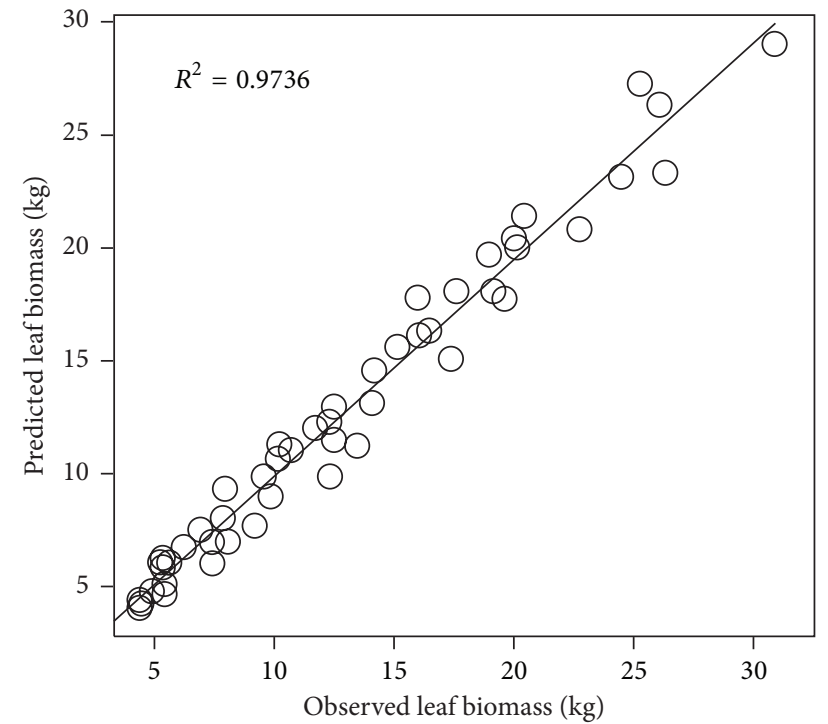

(b)

FIGURE 4: Linear regression between observed and predicted leaf area (a); between observed and predicted leaf biomass (b).

also show that allometric models are explained for more than $95 \%$ of the variation based on DBH with $A_{1}$ and $B_{1}$. L. speciosa is the dominant and medium sized deciduous tree species in tropical semievergreen forest of Bangladesh. Thus, this study is important to tree growth models of this species and ecological purposes, including light interception, transpiration rate, biomass estimation, and carbon storage. As a result, I suggest estimating $A_{1}$ and $B_{1}$ of this species based on available standard inventory measurements such as $\mathrm{DBH}$ and tree height in Bangladesh.

\section{Conclusion}

The consequences of this result showed a strong statistical dependence and best fitted models $\left(\mathrm{M}_{10}\right.$ and $\left.\mathrm{M}_{22}\right)$ between $A_{1}$ and $B_{1}$ with $\mathrm{DBH}$ and $H$. These models can be used effectively at the stand level for estimation of $A_{1}$ and $B_{1}$ of $L$. speciosa quickly, accurately, and nondestructively. Therefore, I propose that the models obtained and validated in this study could be employed with confidence by foresters, forest ecologists, and other scientists for estimating leaf area and leaf biomass in Bangladeshi reserve forests.

\section{Conflict of Interests}

The author declares that there is no conflict of interests regarding the publication of this paper.

\section{Acknowledgment}

The author wish to thank field staffs of the Divisional Forest Office, Sylhet, for their assistance during the field works.

\section{References}

[1] H. Pretzsch, P. Biber, and J. Durský, "The single tree-based stand simulator SILVA: construction, application and evaluation," Forest Ecology and Management, vol. 162, no. 1, pp. 3-21, 2002.

[2] S. A. Pietsch, H. Hasenauer, and P. E. Thornton, "BGC-model parameters for tree species growing in central European forests," Forest Ecology and Management, vol. 211, no. 3, pp. 264-295, 2005.

[3] M. J. Lexer, K. Hönninger, H. Scheifinger et al., "The sensitivity of Austrian forests to scenarios of climatic change: a largescale risk assessment based on a modified gap model and forest inventory data," Forest Ecology and Management, vol. 162, no. 1, pp. 53-72, 2002.

[4] H. Margolis, R. Oren, D. Whitehead, and M. R. Kaufmann, "Leaf area dynamics ofconifer forests," in Ecophysiology of Coniferous Forests, W. K. Smith and T. M. Hinckley, Eds., pp. 255-308, Academic Press, San Diego, Calif, USA, 1995.

[5] R. H. Waring and W. H. Schlesinger, Forest Ecosystems: Concepts and Management, Academic Press, London, UK, 1985.

[6] B. Tobin, K. Black, B. Osborne, B. Reidy, T. Bolger, and M. Nieuwenhuis, "Assessment of allometric algorithms for estimating leaf biomass, leaf area index and litter fall in different-aged Sitka spruce forests," Forestry, vol. 79, no. 4, pp. 453-464, 2006.

[7] J. H. C. Cornelissen, S. Lavorel, E. Garnier et al., "A handbook of protocols for standardised and easy measurement of plant functional traits worldwide," Australian Journal of Botany, vol. 51, no. 4, pp. 335-380, 2003.

[8] J. M. Norman and G. S. Campbell, "Canopy structure," in Plant Physiologicalecology: Field Methods and Instrumentation, R. W. Pearcy, J. Ehleringer, H. A. Mooney, and P. W. Rundel, Eds., pp. 301-325, Chapman and Hall, New York, NY, USA, 1989.

[9] S. K. Sarker, N. Das, M. Q. Chowdhury, and M. M. Haque, "Developing allometric equations for estimating leaf area and leaf biomass of Artocarpus chaplasha in Raghunandan Hill Reserve, Bangladesh," Southern Forests, vol. 75, pp. 51-57, 2013. 
[10] P. A. Gajardo-Caviedes, M. A. Espinosa, U. D. T. Gonzalez, and D. G. Ríos, "The influence of thinning and tree size on the sapwood area/leaf area ratio in coigue," Canadian Journal of Forest Research, vol. 35, no. 7, pp. 1679-1685, 2005.

[11] N. M. Good, M. Paterson, C. Brack, and K. Mengersen, "Estimating tree component biomass using variable probability sampling methods," Journal of Agricultural, Biological, and Environmental Statistics, vol. 6, no. 2, pp. 258-267, 2001.

[12] M. Mencuccini and L. Bonosi, "Leaf/sapwood area ratios in Scots pine show acclimation across Europe," Canadian Journal of Forest Research, vol. 31, no. 3, pp. 442-456, 2001.

[13] K. J. Niklas, "A phyletic perspective on the allometry of plant biomass-partitioning patterns and functionally equivalent organ-categories," New Phytologist, vol. 171, no. 1, pp. 27-40, 2006.

[14] J. H. Zar, "Calculation and miscalculation of the allometric equation as a model inbiological data," BioScience, vol. 18, pp. 1118-1120, 1968.

[15] A. J. Kerkhoff and B. J. Enquist, "Multiplicative by nature: why logarithmic transformation is necessary in allometry," Journal of Theoretical Biology, vol. 257, no. 3, pp. 519-521, 2009.

[16] D. K. Das and M. K. Alam, Trees of Bangladesh, Bangladesh Forest Research Institute, Chittagong, Bangladesh, 2001.

[17] BBS/UNDP (Bangladesh Bureau of Statistics/United Nations DevelopmentProgramme), Compendium of Environment Statistics of Bangladesh, Ministry of Planning, Dhaka, Bangladesh, 2005.

[18] J. C. Malaker, M. M. Rahman, A. K. M. Azad-ud-doula, S. K. Malaker, and M. A. H. Khan, "Floristic composition of Lawachara Forest in Bangladesh," International Journal of Experimental Agriculture, vol. 1, pp. 1-9, 2010.

[19] Asiatic Society of Bangladesh (A S B), Encyclopedia of Flora and Fauna of Bangladesh, Asiatic Society of Bangladesh, Dhaka, Bangladesh, 2007.

[20] J. C. Calvo-Alvarado, N. G. McDowell, and R. H. Waring, "Allometric relationships predicting foliar biomass and leaf area:sapwood area ratio from tree height in five Costa Rican rain forest species," Tree Physiology, vol. 28, no. 11, pp. 1601-1608, 2008.

[21] C. Dobbs, J. Hernández, and F. Escobedo, "Above ground biomass and leaf area models based on a non destructive method for urban trees of two communes in central chile," Bosque, vol. 32, no. 3, pp. 287-296, 2011.

[22] S. K. Sarker, J. C. Deb, and M. A. Halim, "A diagnosis of existing logging bans in Bangladesh," International Forestry Review, vol. 13, no. 4, pp. 461-475, 2011.

[23] K. P. Burnham and D. R. Anderson, Model Selection and Inference: A PracticalInformation-Theoretic Approach, Springer, New York, NY, USA, 2002.

[24] B. R. Parresol, "Assessing tree and stand biomass: a review with examples and critical comparisons," Forest Science, vol. 45, no. 4, pp. 573-593, 1999.

[25] G. M. Furnival, "An index for comparing equations used in constructing volume tables," Forest Science, vol. 7, pp. 337-341, 1961.

[26] S. Chatterjee and A. S. Hadi, Regression Analysis by Example, JohnWiley \& Sons, New Jersey, NJ, USA, 2006.

[27] G. L. Baskerville, "Use of Logarithmic regression in the estimation of plant biomass," Canadian Journal of Forest Research, vol. 2, no. 1, pp. 49-53, 1972.
[28] D. G. Sprugel, "Correcting for bias in log-transformed allometric equations," Ecology, vol. 64, no. 1, pp. 209-210, 1983.

[29] M. Morisita, "Measuring of interspecific association and similarity between communities," Memoirs of the Faculty of Science of Kyushu University E: Biology, vol. 3, pp. 65-80, 1959.

[30] E. P. Smith and K. A. Rose, "Model goodness-of-fit analysis using regression and related techniques," Ecological Modelling, vol. 77, no. 1, pp. 49-64, 1995.

[31] D. I. Warton, D. S. Falster, and M. Westoby, Bivariate Line Fitting Methods Forallometry, Department of Biological Sciences, Macquarie University, Sydney, Australia, 2005.

[32] A. J. Burton, K. S. Pregitzer, and D. D. Reed, "Leaf area and foliar biomass relationships in northern hardwood forests located along an $800 \mathrm{~km}$ acid deposition gradient," Forest Science, vol. 37, pp. 1041-1059, 1991.

[33] K. T. Grace, "Leaf area allometry and evaluation of nondestructive estimates of total leaf area and loss by browsing in a silvopastoral system," Agroforestry Systems, vol. 40, no. 2, pp. 139-147, 1998.

[34] D. Whitehead, W. R. N. Edwards, and P. G. Jarvis, "Conducting sapwood area, foliage area, and permeability in mature trees of Picea sitchensis and Pinus contorta," Canadian Journal of Forest Research, vol. 14, no. 6, pp. 940-947, 1984.

[35] M. G. Keane and G. F. Weetman, "Leaf area-sapwood crosssectional arearelationships in repressed stands of lodgepole pine," Canadian Journal of Forest Research, vol. 17, pp. 205-209, 1987.

[36] D. P. Turner, S. A. Acker, J. E. Means, and S. L. Garman, "Assessing alternative allometric algorithms for estimating leaf area of Douglas-fir trees and stands," Forest Ecology and Management, vol. 126, no. 1, pp. 61-76, 2000.

[37] H. Peter, E. Otto, and S. Hubert, "Leaf area of beech (Fagus sylvatica L.) from different stands in eastern Austria studied by randomized branch sampling," European Journal of Forest Research, vol. 129, no. 3, pp. 401-408, 2010.

[38] R. H. Waring, P. E. Schroeder, and R. Oren, "Application of the pipe model theory to predict canopy leaf area," Canadian Journal of Forest Research, vol. 12, no. 3, pp. 556-560, 1982.

[39] J. N. Long and F. W. Smith, "Leaf area-sapwood area relations of lodgepole pine as influenced by stand density and site index," Canadian Journal of Forest Research, vol. 18, no. 2, pp. 247-250, 1988.

[40] J. H. Fownes and R. A. Harrington, "Allometry of woody biomass and leaf area infive tropical multipurpose trees," Journal of Tropical Forest Science, vol. 4, pp. 317-330, 1991.

[41] D. Zianis and M. Mencuccini, "Aboveground biomass relationships for beech (Fagus moesiaca Cz.) trees in Vermio Mountain, Northern Greece, and generalised equations for Fagus sp," Forest Science, vol. 60, no. 5, pp. 439-448, 2003. 

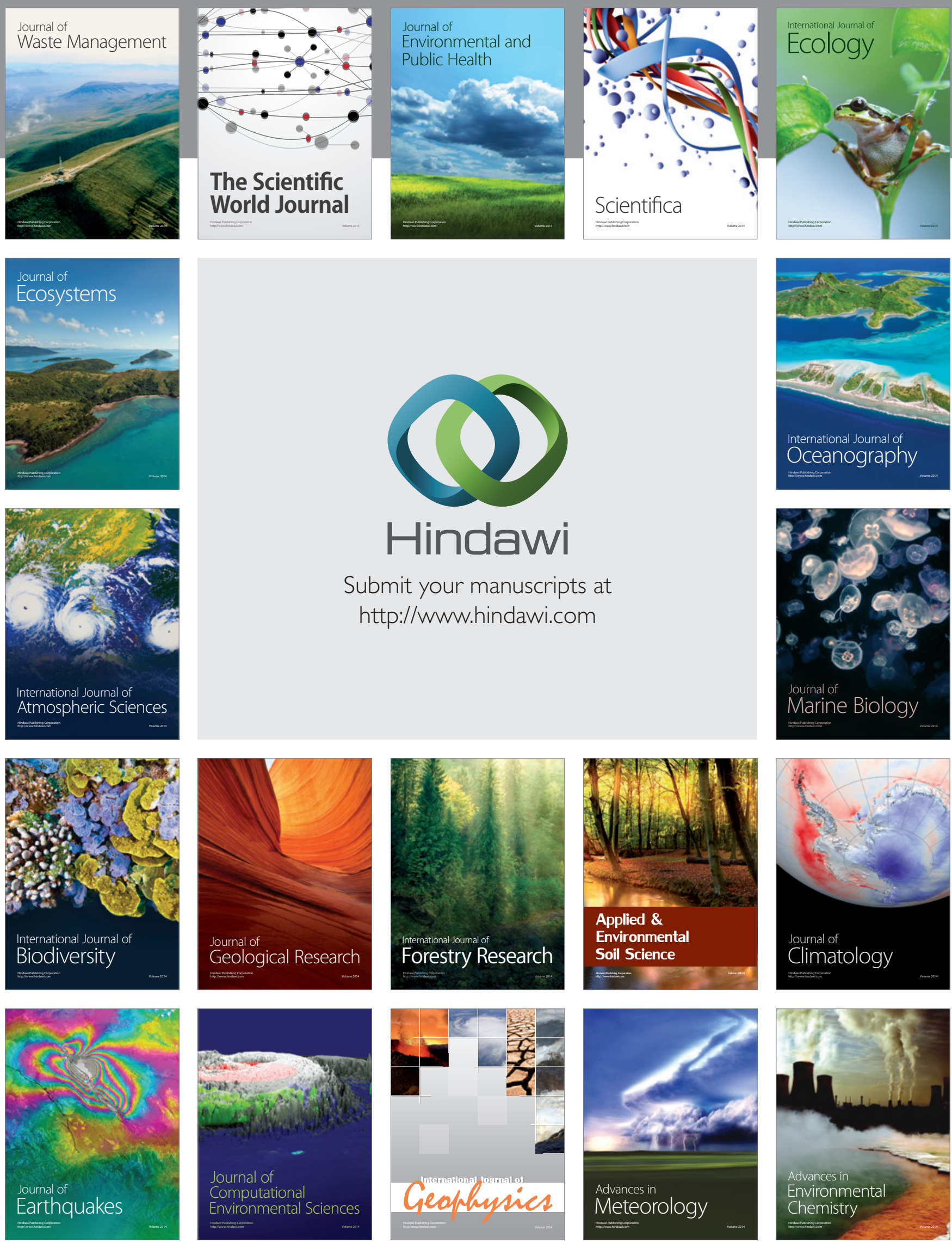